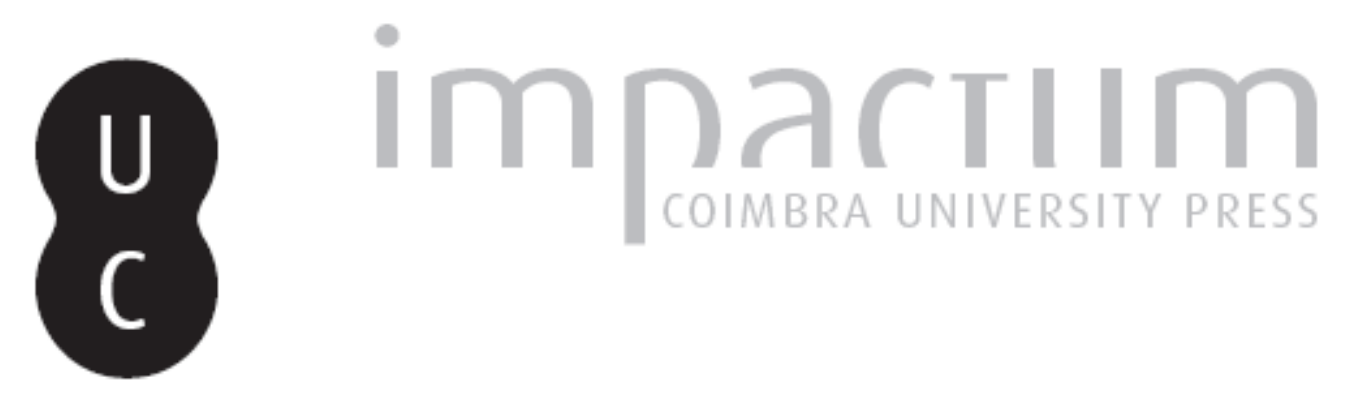

\title{
Um otium cruciatum
}

\section{Autor(es): $\quad$ Schiappa, Maria Teresa}
Publicado por: Associação Portuguesa de Estudos Clássicos; Instituto de Estudos Clássicos

URL persistente:

URI:http://hdl.handle.net/10316.2/30438

DOI:

DOI:http://dx.doi.org/10.14195/0872-2110_51_10

Accessed : $\quad$ 26-Apr-2023 10:28:06

A navegação consulta e descarregamento dos títulos inseridos nas Bibliotecas Digitais UC Digitalis, UC Pombalina e UC Impactum, pressupõem a aceitação plena e sem reservas dos Termos e Condições de Uso destas Bibliotecas Digitais, disponíveis em https://digitalis.uc.pt/pt-pt/termos.

Conforme exposto nos referidos Termos e Condições de Uso, o descarregamento de títulos de acesso restrito requer uma licença válida de autorização devendo o utilizador aceder ao(s) documento(s) a partir de um endereço de IP da instituição detentora da supramencionada licença.

Ao utilizador é apenas permitido o descarregamento para uso pessoal, pelo que o emprego do(s) título(s) descarregado(s) para outro fim, designadamente comercial, carece de autorização do respetivo autor ou editor da obra.

Na medida em que todas as obras da UC Digitalis se encontram protegidas pelo Código do Direito de Autor e Direitos Conexos e demais legislação aplicável, toda a cópia, parcial ou total, deste documento, nos casos em que é legalmente admitida, deverá conter ou fazer-se acompanhar por este aviso. 


\section{Boletim de}

\section{Estudos Clássicos}

Associação Portuguesa de Estudos Clássicos Instituto de Estudos Clássicos

Coimbra

Junho de 2009 


\section{UM OTIVM CRVCIATVM}

Retomamos uma proposta de palavras cruzadas latinas, apresentada em tempos, cuja utilidade tivemos uma ou outra vez ocasião de testar, num âmbito não muito avançado da Iniciação ao Latim. O nosso objectivo era então fixar os usos de determinados conectores, pronomes e advérbios interrogativos, fazendo depender do cruzamento das palavras a verificação de outros termos, eventualmente remissíveis para itens linguísticos ainda não estudados (como o verbo ire). Embora com esta limitação, o exercício aí incluído coaduna-se com uma fase não muito avançada de aprendizagem, que tenha partido da prática dos referidos elementos, predominantemente num contexto de oralidade onde o sistema de pergunta/ resposta contribui, de forma decisiva, para abarcar circunstâncias elementares de lugar, tempo, causa, etc.

A proposta que aqui trazemos é, nesse aspecto, diversa. Partiu concretamente da dificuldade sentida por alunos, já em fases mais adiantadas do estudo da língua, em reconhecerem (e fixarem) alguns verbos depoentes sobretudo de tema em -i- e em consoante - que costumo agrupar para exercícios de conjugação: proficisci, gradi e compostos (aggredi, progredi, ingredi, regredi, etc.). $\mathrm{O}$ treino inicial destes verbos é importante para o reconhecimento e consolidação dos depoentes que regem ablativo, em particular $u t i$, que apresenta, aliás, uma sinonímia - por vezes incómoda ... com $u t i$ conjunção $(=u t)$. Nesta fase posterior pressupomos já também o domínio da flexão verbal do conjuntivo (pelo menos, presente) e da flexão nominal. Neste último caso, além de uma palavra de tema em -ü- (anus, us "velha", cf. port. anoso), encontramos também outras de tema em -i- e em consoante mais complexas (uis, uis, latus, eris), que implicam já uma perspectiva global da $3^{\text {a }}$ declinação.

A concepção deste tipo de exercício só ocasionalmente consegue concretizar a inclusão estrita de itens leccionados antes. Se a homonímia entre uis substantivo e uis, $2^{\text {a }}$ pes. do sing. do presente do indicativo de uelle, é pacífica, talvez o mesmo não suceda com a forma oderis, a menos que tenham já ocorrido verbos defectivos que usam o perfeito com valor de 
presente (incluindo o perfeito do conjuntivo). O mesmo pode acontecer com as condicionais $\sin$ ou nisi, bem como com o dat./ ablat. pl. contracto is (= iis), também $2^{\text {a }}$ pes. sing. do presente do indicativo de ire. Ao docente caberá decidir se é oportuno aproveitar este tipo de exercícios como motivação para o desenvolvimento gramatical de um ou outro dos itens não leccionados. $\mathrm{O}$ presente do indicativo do v. uelle, por exemplo, poderá ser apresentado e memorizado neste contexto, bem como os perfeitos completos do tipo de odi, se o modo conjuntivo, nos verbos regulares, já tiver sido sistematizado. Será certamente esse o caso, numa etapa linguística que comporte o estudo do texto que inspirou o presente exercício - o conhecido passo autobiográfico do Brutus de Cícero ( $\$ 316-317)$, cujas particularidades vocabulares incluem

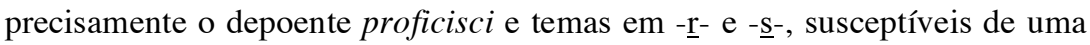
revisão global.

No tocante a esse vocabulário aqui representado, será sempre útil insistir na homonímia entre profectus, part. passado de proficisci ("partir", "ir embora") e substantivo proveniente de proficere ("ser útil") com a significação de "progresso", "proveito". São palavras diversas, que o dicionário diferencia por números: profectus 1 [proficiscor] e profectus 2 [proficio]. Latus, eris é também uma palavra a reter, não só pelo valor específico do plural, "pulmões" (isto é, órgão duplo, que se situa de um e outro lado do corpo) como pela sua representação em português (lat. vulgar *latu- > port. lado, cf. lateral, por via erudita).

Se oportuno, poderá assinalar-se a passagem regular deste tipo de palavras neutras em -us à declinação dos temas em -o- no latim vulgar, como acontece também com tempus, oris, que passou a*tempus, $i$, port. tempo, cf. temporal. À confusão das declinações junta-se neste caso o gradual desaparecimento do neutro, incluído, na maior parte dos casos, no masculino, uma tendência já ocasionalmente verificável nas inscrições do período arcaico e clássico, bem como na linguagem coloquial dos libertos da Cena Trimalchionis (e. g. Petrónio, Satyricon, §41.12, passim: uinus por uinum). 


\section{uerba cruciata - exercitatio secunda}

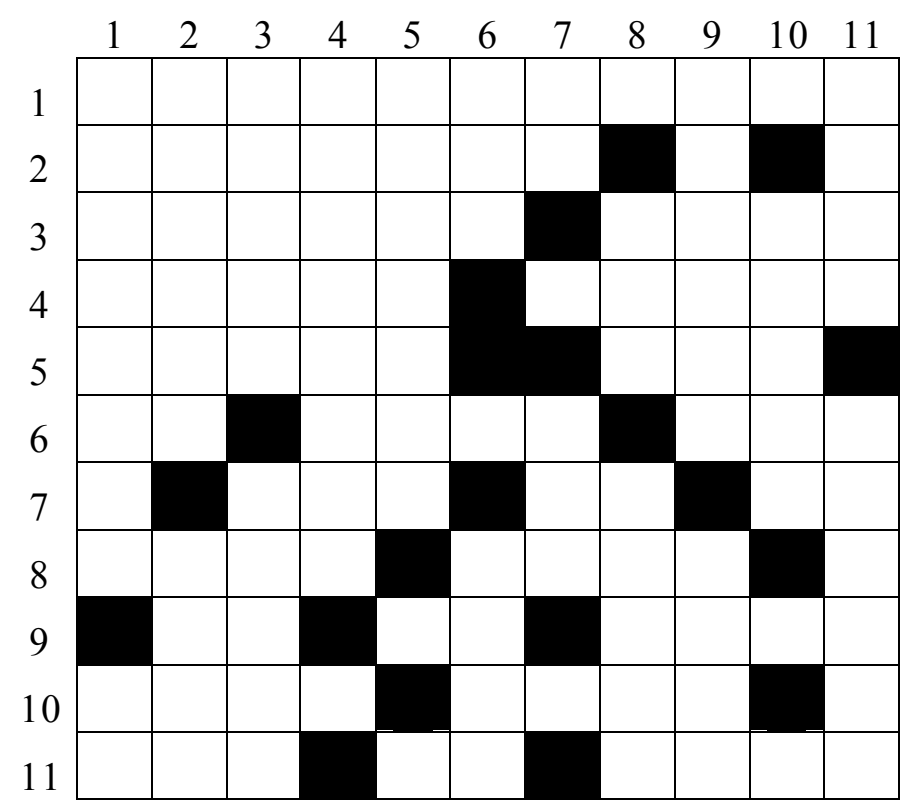

\section{Horizontais:}

1. (Que eu) parta. 2. Dim. de ripa (dat. pl.). 3. (Que) odeies. À cidade. 4. Tratas de/ fazes. Homens (acus.). 5. Raias. Se pelo contrário. 6. És/ estás. Ruga (sobrenome romano). 7. Com/ quando (+ indicat.). Forma contracta de nisi. Ela/estas coisas. 8. O mesmo. Que/ o que. 9. Conjunção integrante/ partícula interrogativa $(=-n e)$. Quatro em romanos. Retira-te/ cede! 10. Únicas (acus.). Junto de/ em casa de. 11. Ide! Equivalente a aut. Tardia.

\section{Verticais:}

1. Avançar. Seis em romanos. 2. (Que) rias. Dão. 3. Obra/ trabalho (dat. sing.). Do jantar. 4. Das Fúrias. 5. Rio que banhava Atenas (acus.). 6. Prefixo que designa "aquém". As quais. 7. Vais/ forma contracta do dat. e ablat. pl. do pron. is. Velha (ablat.). 8. Queres/ força (subst.). Gracejo/ brincadeira. 9. Com os carros. Dá (de uma vez por todas)! 10. Boas. 11. Derrubas. Pulmões (acus.). 
NB: a) As palavras de uma mesma fila são separadas por pontos;

b) indicamos valores diferentes da mesma palavra por uma barra oblíqua.

\section{Horizontais:}

\section{SOLUÇÕES}

1. PROFICISCAR. 2. RIPVLIS. 3. ODERIS. VRBI. 4. GERIS. VIROS. 5. RAIAS. SIN. 6. ES. RVGA. SAL. 7. CVM. NI. EA. 8. IDEM. QVOD. 9. AN. IV. CEDE. 10. VNAS. APVD. 11. ITE. VE. SERA.

\section{Verticais:}

1. PROGREDI. VI. 2. RIDEAS. DANT. 3. OPERI. CENAE. 4. FVRIARVM. 5. ILISSVM. 6. CIS. QVAE. 7. IS. ANV. 8. VIS. IOCVS. 9. CVRRIS. DEDE. 10. BONAE. 11. RVIS. LATERA.

MARIA TERESA SCHIAPPA 